\title{
Height estimation based on second cervical vertebra measured using three-dimensional computed tomographic scanning in Iranian adults
}

\author{
Seyed Reza Saadat Mostafavi ${ }^{1}$, Azadeh Memarian ${ }^{2 *}$, Omid Motamedi ${ }^{1}$, Mohammadreza Khaleghi ${ }^{1}$ \\ and Mehdi Pouromidi ${ }^{3}$
}

\begin{abstract}
Objectives: The cervical vertebrae are more durable than other skeletal components, and therefore may be the only remnants of a dead body. The present study aims to investigate the role of several linear dimensions of the second cervical vertebrae measured by Three-Dimensional Computed Tomographic Scanning (3D CT Scan) in height estimation of Iranian adult population. In this cross-sectional study, height determination was performed by measuring 15 indexes of the second cervical vertebrae. Indexes were obtained by screening cervical CT scan of 66 patients (33 males and 33 females) aged $\geq 18$ years at Rasoul Hospital. Chi square, T student and logistic regression tests were used for statistical analysis. The significance level was considered to be $<0.05$.

Result: In the total population, among the indexes for the second cervical vertebrae, the Max height of the axis (AMA) $(r=0.470, P=0.0001)$, Max length of the axis $(C M A)(r=0.320, P=0.007)$, and Sagittal max body diameter (DSMC) $(r=0.281, P=0.019)$ had a strong and positive correlation with height. The results of this study showed the accuracy of linear dimensions of cervical vertebrae in determining the body height of the Iranian adult population.
\end{abstract}

Keywords: Body height, Cervical vertebrae, Tomography, X-ray computed, Linear dimensions

\section{Introduction}

Forensic anthropology tries to define the identity of corpses. Since bones remain several years after death, the skeletal examination could be especially useful to identify those cases $[1,2]$. Height is the main component in the construction of the biological profile of an individual and is one of the basic actions to identify is to determine the height of the individual once remains are found $[3,4]$. There are various approaches to use a metrical study of skeletal remains to define the height. However, the best outcomes are obtained from the remains of long bones $[3,5-8]$. Though in most of the times, we do not have long bones or they are fragmented, while smaller bones,

\footnotetext{
*Correspondence: memarian.a@iums.ac.ir

${ }^{2}$ Department of Forensic Medicine, Iran University of Medical Sciences, Tehran, Iran

Full list of author information is available at the end of the article
}

such as vertebrae, preserve better [9]. Therefore, studies performed on the spinal column to estimate height from the spinal column segments $[10,11]$.

The relationship between heights of people with spinal vertebrae morphology is one of the effective factors in identifying a person in forensic medicine. For this reason, in cases where only part of the body spine is available, the morphology of the vertebral column can explain the various skeletal features of a person, including his height. Different calculations on the vertebral column in different areas of the neck, chest and lumbar determine various skeletal characteristics of individuals. Each component of the spinal cord at any portion, especially in the cervical area, can be of great help in identifying height, especially in cases where it is not possible to assess height, such as severe traumas $[3,12-14]$. 
However, identification using the skeletal remains is subject to many limitations. For example, in many cases, skeletal remains are not coherent, fragmented or have changed the process of corruption. Also, due to differences in the biology of different individuals, the genetic, ethnic and the environment it is not possible to generalize the result of the studies limited to specific populations to other people [12, 15]. According to our search, there is a limited study on using the indexes of the second cervical vertebrae and there is no study in Iranian population. Therefore, the study aims to estimate the height based on the measurement of the indexes of the second cervical vertebra using Three-Dimensional Computed Tomographic Scanning (3D CT) scan in the Iranian adult population.

\section{Main text Methods}

This is a cross-sectional study. In this study 66 individuals (33 male and 33 female) aged $\geq 18$ years who underwent cervical vertebrae CT scan in Rasoul Akram Hospital were selected randomly. A randomized sampling method was used and all participants signed informed consent.

The sample size was determined according to Vasavada study in 2008 , the mean height of seven cervical vertebrae in male and female were $24.6 \pm 2.7 \mathrm{~mm}$ and $22.6 \pm 2.4 \mathrm{~mm}$, respectively. By considering a confidence interval of 0.05 and the study power of $90 \%$, the required sample size for this study was 33 for male and 33 for female:

$$
\begin{aligned}
& \mathrm{n}_{1}=\mathrm{n}_{2}=\left(\mathrm{S}_{1}^{2} \pm \mathrm{S}_{2}^{2}\right)\left(\mathrm{Z}_{1-\alpha / 2} \pm \mathrm{Z}_{1-\beta}\right) /\left(\mathrm{X}_{1}^{-} \pm \mathrm{X}_{2}^{-}\right)^{2} \\
& \mathrm{X} 1=24.6, \mathrm{X} 2=22.6 \\
& \mathrm{~S} 1=2.7, \mathrm{~S} 2=2.4 \\
& \mathrm{Z} 1-\alpha / 2=1.96, \mathrm{Z} 1-\beta=1.29 \\
& \mathrm{n} 1=\mathrm{n} 2=33
\end{aligned}
$$

The exclusion criteria were as follow: age under 18 years, a history of congenital anomalies in the cervical spine, a history of trauma to the neck with any severity, a history of structural, metabolic or rheumatologic disorders in the cervical spine, a history of any surgical or therapeutic intervention in the neck area.

The linear dimensions of the second cervical vertebrae were measured using three dimensional CT scan (Slice, Toshiba, Japan) with Multi-Planar Reconstruction (MPR) and Volume Rendering at sagittal and horizontal sections. The thickness of the slices was $1 \mathrm{~mm}$. Fifteen indexes of the second cervical vertebrae were measured: Max height of the axis (AMA), Max length of the axis (CMA), Odontoid process sagittal diameter (DSD), Odontoid process transverse diameter (DTD), Max distance between the superior facets (DMFS), Max length of the sup. Facet (CMFS), Max width of sup. Facet (LMFS), Length of the vertebral foramen (CMFV), Sagittal max body diameter (DSMC), Max width of the vertebral foramen (LMFV), Max height of the odontoid process (AMD), Max transverse diameter of the body (DTMC), Max width of the axis (LMA), Max length of the inf. Facet (CMFI), and Max width of the inf. Facet (LMFI). Then, the evaluated indexes were compared in different age groups and the diagnostic accuracy of each index for height estimation was evaluated. Figure 1 shows the schematic view of the dimensions measured in the second cervical vertebrae.

\section{Statistical analysis}

Data were analyzed using SPSS version 23. For quantitative variables, $T$ test was used to compare the data, and the Pearson correlation test was used to investigate the relationship between height and second cervical vertebrae indexes. Values were significant at $\mathrm{P}<0.05$.

The Kolmogorov-Smirnov test (K-S) test was used to determine the normal distribution of data.

\section{Results}

The mean age of the participants was $40.91 \pm 14.85$ years old and the age range was between 18 to 83 years. The mean age of female was $40.54 \pm 14.07$ years and the mean age of male was $41.82 \pm 16.38$ years. There was no significant difference in age between male and female $(\mathrm{P}=0.938)$.

In the present study 15 , indexes of the second cervical vertebrae were measured. To investigate the relationship between height and second cervical vertebrae indexes, due to the normal distribution of data, the Pearson correlation test was used in the total population, and the results are summarized in Table 1 . In the total population, among the indexes for the second vertebrae, only the AMA $(r=0.470, P=0.0001)$, CMA $(r=0.320$, $\mathrm{P}=0.007)$, and DSMC $(\mathrm{r}=0.281, \mathrm{P}=0.019)$ had a strong and positive correlation with height.

To investigate the relationship between age and the indexes of the second cervical vertebrae, due to the normal distribution of data, the Pearson correlation test was used in the total population and each sex, and the results are summarized in Table 2. In the total population, only DTD, DMFS, and DSMC indexes of the second cervical vertebra had a weak and positive correlation with age. There was no significant correlation between age and the second cervical vertebra indexes in male. A moderate significant positive correlation was observed in female 

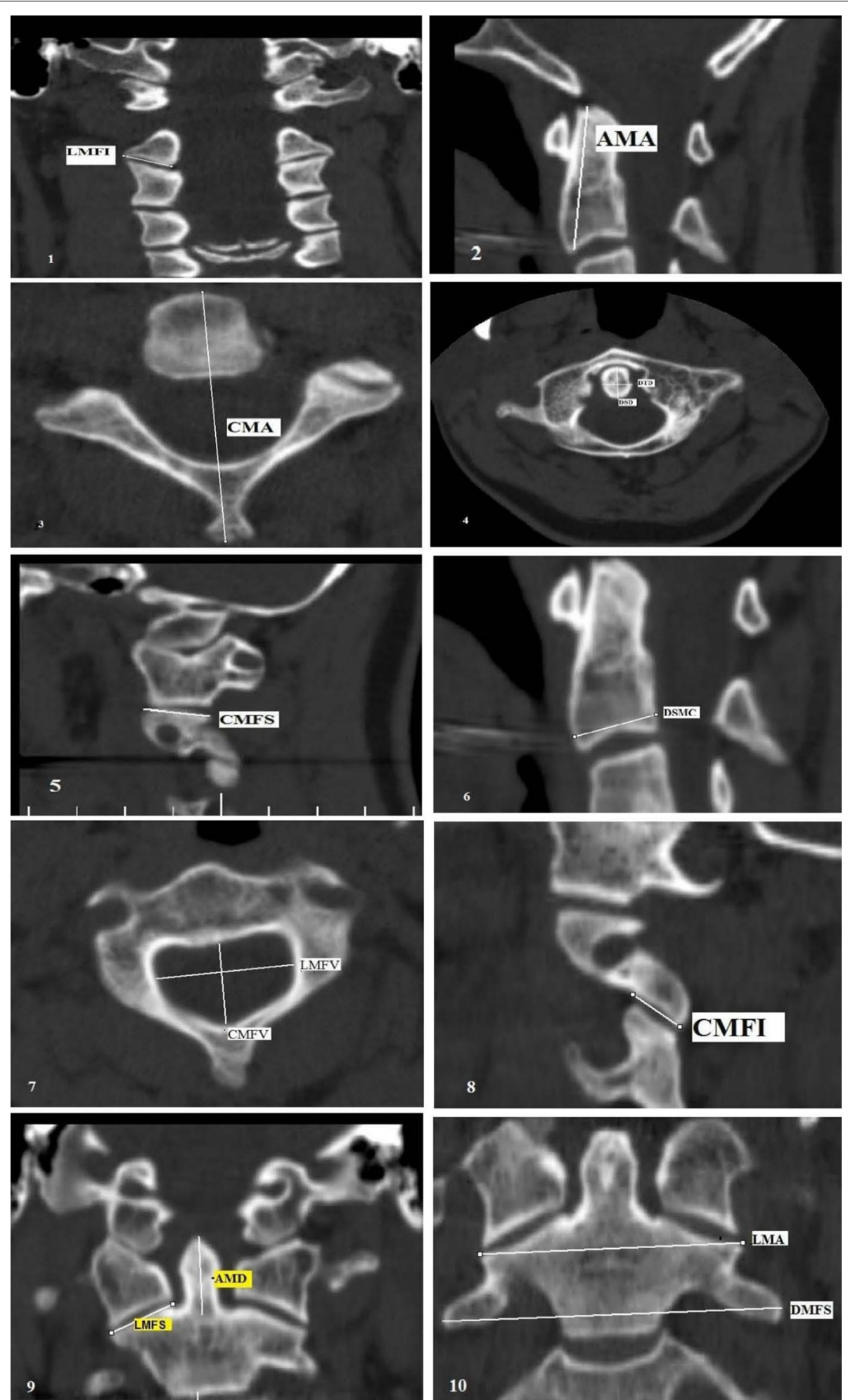

Fig. 1 The Measured Dimensions of the Second Cervical Vertebrae in the (1) Coronal (LMFI): max width of the inf. Facet (2) AMA (max hight of the axis) (3) CMA. max length of the axis (4) Axial (DTD, DSD) odontoid process transverse diameter, odontoid process sagittal diameter 5) CMFS (max length of the sup. Facet) (6) DSMC. sagittal max body diameter (7) Axial (LMFV, CMFV) max width of the vertebral foramen, max length of the vertebral foramen (8) CMFI. (max length of the inf. Facet) (9) Cronal (AMD, LMFS) (max height of the odontoid process) (max width of the sup. Facet) (10) Coronal (LMA, DMFS): max width of the axis, max distance between the superior facets 
Table 1 Correlation between height and indices related to the second cervical vertebrae in the total population

\begin{tabular}{lll}
\hline Indexes & Correlation coefficient & P value \\
\hline AMA & 0.470 & 0.0001 \\
CMA & 0.320 & 0.007 \\
LMA & 0.085 & 0.483 \\
DSD & 0.064 & 0.598 \\
DTD & 0.031 & 0.801 \\
DMFS & 0.202 & 0.093 \\
CMFS & 0.170 & 0.161 \\
LMFS & 0.126 & 0.298 \\
CMFV & 0.095 & 0.434 \\
LMFV & 0.048 & 0.694 \\
AMD & 0.133 & 0.271 \\
DSMC & 0.281 & 0.019 \\
DTMC & 0.089 & 0.462 \\
CMFI & 0.056 & 0.644 \\
LMFI & 0.223 & 0.063 \\
\hline
\end{tabular}

between age and CMA, LMA, DTD, DMFS, and CMFS indexes.

\section{Discussion}

In this study, for the first time, the dimensions of the second cervical vertebrae were used in the determination of the height in the mature and living population of Iran using their cervical CT scan. The relationship between heights of persons with spinal vertebra morphology is one of the effective factors in identifying a person in forensic medicine. For this reason, in cases where only part of the body spine is available, the morphology of the vertebral column can explain the various skeletal features of a person, including his height.

In this study, 15 indexes of second cervical vertebra and their relationship with height were investigated. In 3 indexes, this difference was statistically significant. These three indexes were AMA, CMA, and DSMC. Torimitsu et al. evaluated the height estimation in Japanese by measuring second cervical vertebra using a multidetector computed tomography (MDCT). They showed that All measurements of the $\mathrm{C} 2$ including the length from the top of the dens to the anteroinferior point of the vertebral body (DA), the length from the top of the dens to the posterior point of the spinous process (DS), and the length from the anteroinferior point of the vertebral body to the posterior point of the spinous process (AS), were positively correlated with height. The highest correlation was detected for the DA $(r=0.762)$, and the lowest correlation was seen for AS $(r=0.684)$. Besides, the standard errors of the estimate were large. They showed the size of the $\mathrm{C} 2$ as measured with MDCT images may be useful for stature estimation [11]. In a study by Rodríguez et al. the height estimation was performed from the first and second cervical vertebrae in a Spanish population. The best results were gained in all three groups, males, females and total population, by the four measures of the first (Height of vertebra (V) + Interforaminal length (I)) and second (Greatest-diameter dens (DO) + Height of the odontoid $(\mathrm{O})$ ) cervical vertebrae. For estimating height for females the determination coefficient was somewhat

Table 2 Correlation between age and indexes related to the second cervical vertebra

\begin{tabular}{|c|c|c|c|c|c|c|}
\hline \multirow[t]{2}{*}{ Indexes } & \multicolumn{2}{|l|}{ Male } & \multicolumn{2}{|l|}{ Female } & \multicolumn{2}{|l|}{ Total } \\
\hline & Correlation coefficient & $P$ value & Correlation coefficient & $P$ value & Correlation coefficient & $P$ value \\
\hline AMA & -0.046 & 0.792 & 0.125 & 0.474 & 0.014 & 0.91 \\
\hline CMA & -0.115 & 0.511 & 0.383 & 0.023 & 0.135 & 0.267 \\
\hline LMA & 0.087 & 0.618 & 0.361 & 0.033 & 0.242 & 0.043 \\
\hline DSD & 0.132 & 0.449 & 0.119 & 0.494 & 0.107 & 0.38 \\
\hline DTD & 0.030 & 0.864 & 0.353 & 0.037 & 0.240 & 0.046 \\
\hline DMFS & -0.025 & 0.888 & 0.406 & 0.016 & 0.237 & 0.048 \\
\hline CMFS & 0.001 & 0.997 & 0.388 & 0.021 & 0.209 & 0.083 \\
\hline LMFS & 0.183 & 0.292 & 0.202 & 0.244 & 0.167 & 0.166 \\
\hline CMFV & -0.198 & 0.254 & 0.069 & 0.696 & -0.067 & 0.582 \\
\hline LMFV & -0.091 & 0.604 & 0.159 & 0.361 & 0.033 & 0.788 \\
\hline AMD & 0.222 & 0.200 & 0.092 & 0.599 & 0.150 & 0.217 \\
\hline DSMC & 0.318 & 0.063 & 0.321 & 0.060 & 0.272 & 0.023 \\
\hline DTMC & 0.018 & 0.919 & 0.014 & 0.936 & 0.013 & 0.914 \\
\hline CMFI & 0.168 & 0.335 & 0.244 & 0.158 & 0.211 & 0.80 \\
\hline LMFI & 0.083 & 0.635 & 0.203 & 0.243 & 0.130 & 0.285 \\
\hline
\end{tabular}


higher by the measurements of $\mathrm{C} 2$ than $\mathrm{C} 1$. Though, for male both determination coefficients are equal [16].

In a study by Nagesh et al., the stature in South Indians was estimated from vertebral column length. According to the result of the logistic regression test in this study, the value of the correlation coefficient for height estimation from the cervical segment was 0.583 in males and 0.325 in females. This study showed that height estimates can be made from different parts of the spine, especially cervical vertebrae [10]. In a study by Wu RQ et al. in 2017, on 933 people in the population of the Yangtze River Delta, the dimensions and indices of the cervical vertebrae were evaluated and compared to find its relationship with the height. The analysis of the data showed that the size and dimensions of the neck bones were an appropriate method for the rapid, simple and accurate assessment of height for forensic experts [17]. In a study by Zhang et al. the anterior and posterior heights of C3-C7 were measured in the lateral films of the cervical vertebrae in the male population of Sichuan Han in China. For stature estimation between the cervical vertebrae and height, linear regression analysis was done to establish the regression equations. They showed that all equations were useful to estimate the body height of the adult males [18].

Preceding studies have revealed the accuracy of stature estimation using long bones $[3,5,6]$, but most of the times in disaster, burn, and skeletal traumas it is not possible to collect the intact long bones and other more frequent, smaller and stronger bones like vertebrae should be considered.

Among the second cervical vertebrae indexes, 3 showed a correlation with height. These three indices were AMA, CMA, and DSMC. The results of the current study revealed the accuracy of linear dimensions of cervical vertebrae in determining the height of skeletal remains in the Iranian adult population.

\section{Limitation}

Differences in the body's dimensions can be seen as a confounding factor concerning the dimensions of the vertebrae with height. Because of the limitations in this study, it was not possible to study the body dimensions of the subjects, but in future studies, fitting the body to remove its confounding effect and finding independent variables that determine the height of the dimensions of the vertebrae are suggested.

\section{Abbreviations}

MPR: Multi-Planar Reconstruction; AMA: max height of the axis; CMA: max length of the axis; DSD: odontoid process sagittal diameter; DTD: odontoid process transverse diameter; DMFS: max distance between the superior facets; CMFS: max length of the sup. Facet; LMFS: max width of sup. Facet; CMFV: length of the vertebral foramen; DSMC: sagittal max body diameter;
LMFV: max width of the vertebral foramen; AMD: max height of the odontoid process; DTMC: max transverse diameter of the body; LMA: max width of the axis; CMFI: max length of the inf. Facet; LMFI: max width of the inf. Facet.

\section{Acknowledgements}

There is no acknowledgment for the present study.

\section{Authors' contributions}

RSM and AM designed and managed the project, collected and analyzed data and composed the manuscript. OM managed the project and reviewed/ edited the manuscript. MK reviewed/edited the manuscript. MP reviewed/ edited the manuscript. All the authors participated in approving the final draft of the manuscript. All authors read and approved the final manuscript.

\section{Funding}

No funding was received.

Availability of data and materials

Data are available from corresponding author upon request.

Ethics approval and consent to participate

The study is approved by the ethical committee of Iran University of Medical Sciences and is performed according to Helsinki principals of ethics. Written consent was obtained from patients.

\section{Consent for publication}

Not applicable.

\section{Competing interests}

The authors declare that they have no competing interests.

\section{Author details}

${ }^{1}$ Department of Radiology, Iran University of Medical Sciences, Tehran, Iran.

${ }^{2}$ Department of Forensic Medicine, Iran University of Medical Sciences, Tehran, Iran. ${ }^{3}$ Iran University of Medical Sciences, Tehran, Iran.

Received: 10 July 2019 Accepted: 11 September 2019

Published online: 18 September 2019

\section{References}

1. Yaşar Işcan M. Rise of forensic anthropology. Am J Phys Anthropol. 1988;31:203-29.

2. Memarian A, Aghakhani K, Mehrpisheh S, Fares F. Gender determination from diagnostic factors on anteroposterior pelvic radiographs. J Chin Med Assoc. 2017;80:161-8. https://doi.org/10.1016/j.jcma.2016.06.009.

3. De Mendonca MC. Estimation of height from the length of long bones in a Portuguese adult population. Am J Phys Anthropol. 2000;112:39-48. https://doi.org/10.1002/(SICI)1096-8644(200005)112:1\%3c39:AID-AJPA5 \%3e3.0.CO:2-\%23.

4. Zeybek G, Ergur I, Demiroglu Z. Stature and gender estimation using foot measurements. Forensic Sci Int. 2008;181(54):e1-5. https://doi. org/10.1016/j.forsciint.2008.08.003.

5. Radoinova D, Tenekedjiev K, Yordanov Y. Stature estimation from long bone lengths in Bulgarians. Homo. 2002;52:221-32.

6. Mahakkanukrauh , Khanpetch P, Prasitwattanseree S, Vichairat K, Troy Case D. Stature estimation from long bone lengths in a Thai population. Forensic Sci Int. 2011;210(279):e1-7. https://doi.org/10.1016/j.forsc iint.2011.04.025.

7. Hauser R, Smolinski J, Gos T. The estimation of stature on the basis of measurements of the femur. Forensic Sci Int. 2005;147:185-90. https:// doi.org/10.1016/j.forsciint.2004.09.070.

8. Munoz JI, Linares-Iglesias M, Suarez-Penaranda JM, Mayo M, Miguens $X$, Rodriguez-Calvo MS, et al. Stature estimation from radiographically determined long bone length in a Spanish population sample. J Forensic Sci. 2001:46:363-6.

9. Byers $\mathrm{S}$, Akoshima K, Curran B. Determination of adult stature from metatarsal length. Am J Phys Anthropol. 1989;79:275-9. https://doi. org/10.1002/ajpa.1330790303. 
10. Nagesh KR, Pradeep Kumar G. Estimation of stature from vertebral column length in South Indians. Leg Med (Tokyo). 2006;8:269-72. https:// doi.org/10.1016/j.legalmed.2006.05.007.

11. Torimitsu S, Makino Y, Saitoh H, Sakuma A, Ishii N, Hayakawa M, et al. Stature estimation in Japanese cadavers based on the second cervical vertebra measured using multidetector computed tomography. Leg Med (Tokyo). 2015;17:145-9. https://doi.org/10.1016/j.legalmed.2014.11.003.

12. Gilsanz V, Boechat MI, Gilsanz R, Loro ML, Roe TF, Goodman WG. Gender differences in vertebral sizes in adults: biomechanical implications. Radiology. 1994;190:678-82. https://doi.org/10.1148/radiology.190.3.8115610.

13. Gilsanz V, Kovanlikaya A, Costin G, Roe TF, Sayre J, Kaufman F. Differential effect of gender on the sizes of the bones in the axial and appendicular skeletons. J Clin Endocrinol Metab. 1997;82:1603-7. https://doi. org/10.1210/jcem.82.5.3942.

14. Mosekilde L, Mosekilde L. Sex differences in age-related changes in vertebral body size, density and biomechanical competence in normal individuals. Bone. 1990;11:67-73.

15. Urbani $C$, Lastrucci $R D$, Kramer $B$. The effect of temperature on sex determination using DNA-PCR analysis of dental pulp. J Forensic Odontostomatol. 1999;17:35-9.
16. Rodriguez S, Rodriguez-Calvo MS, Gonzalez A, Febrero-Bande M, MunozBarus JI. Estimating height from the first and second cervical vertebrae in a Spanish population. Leg Med (Tokyo). 2016;19:88-92. https://doi. org/10.1016/j.legalmed.2015.08.002.

17. Wu RQ, Wang T, Shi Q, Xiao B, Ma KJ, Chen X. Adult stature estimation by multiple parameters of body torso segment. Fa Yi Xue Za Zhi. 2017;33:236-8. https://doi.org/10.3969/j.issn.1004-5619.2017.03.004.

18. Zhang ZH, Chang YF, Zhou XR, Deng ZH, Yu JQ, Huang L. Stature estimation from the cervical vertebrae of living male by measuring $X$ ray films of computer radiography. Fa Yi Xue Za Zhi. 2008;24:25-31.

\section{Publisher's Note}

Springer Nature remains neutral with regard to jurisdictional claims in published maps and institutional affiliations.
Ready to submit your research? Choose BMC and benefit from:

- fast, convenient online submission

- thorough peer review by experienced researchers in your field

- rapid publication on acceptance

- support for research data, including large and complex data types

- gold Open Access which fosters wider collaboration and increased citations

- maximum visibility for your research: over $100 \mathrm{M}$ website views per year

At BMC, research is always in progress.

Learn more biomedcentral.com/submissions 